\title{
Social Media Usage by Academics: Some Comparisons from a Developing Country and Developed Countries' Perspectives
}

\author{
Pieter $\mathrm{Nel}^{*}$
}

\begin{abstract}
Academics and students across the globe are increasingly using social media and social connections for educational purposes. This paper focusses on a comparison of particular countries regarding the use of social media in teaching by academics and whether they can utilize this platform for effective communication to engage students in learning activities as well. The objective is to identify the usage of social media tools by academics by comparing a multi developed country study (comprising the UK, Australia, New Zealand, USA, Continental Europe and Canada) and a separate developing country study being South Africa. The data was obtained by using SurveyMonkey and executed during 2014 at tertiary educational institutions. For the developing country 204 usable responses were obtained and 711 responses from the developed countries. Suggestions are made regarding the educational environment using social media tools. It is concluded that academics are communicating with students in a positive way via the use of social media tools for educational purposes, but that much scope exists to improve the use of social media for educational purposes by academics. There are also some differences in the use of social media by academics when comparing the developing country and developed countries.
\end{abstract}

JEL codes: Management

\section{Introduction}

Although it is surprising it remains true that the electronic revolution and particularly the evolution of social media in the contemporary world has increased meteorically since the start of the new millennium. Today it permeates all spheres of life, no matter whether it is digital media being used for a business to speed up recruitment processes and internal communications between staff or the plain use of computers in all spheres of modern domestic and business life (Rahman, Arora \& Kularatne, 2014). The fast moving world of today has also placed new demands on communication systems to accommodate generation $\mathrm{Y}$ in particular who are notoriously impatient because they demand instant feedback on a variety of issues in the social environment.

Dixon (2015:9) claims that worldwide there are over 2 billion users of social media and covers $40 \%$ of all people with an internet connection. Facebook alone has the greatest use with more than 1.3 billion people globally. It is thus clear why academics also embrace electronic media in their teaching to transmit knowledge and to enhance the learning experiences of students. Furthermore, it is generally believed that social media technology usage in teaching enhances student participation, engagement and communication. It also strengthens relationships between academics, students and communities (Retta: 2012).

\footnotetext{
*Prof. Pieter Nel, Department of Management and Marketing, Unitec Institute of Technology, Auckland, New Zealand. Email: pnel@unitec.ac.nz
} 
Young (2014) states that eLearning is the delivery of content to individuals and groups via the Internet and is enabled by the support of Information Computer Technology (ICT). It is unsurprising that eLearning and social media go hand in hand to enhance student learning as means used by academics to enrich students' leaning experiences. Internet based social media technologies are designed and developed to improve social connections of a community. Social media applications include Facebook, Google Plus, YouTube, Pinterest, Twitter, WhatsApp, Snapchat, Instagram and Web Blogs, all of which have become very popular among students and educators.

In view of the growing importance of social media it is clear why the need for the use thereof has been accommodated in the educational environments in various countries (Wiid, Cant \& Nel, 2013; Lupton, 2014).

The objective of this research project is to determine academics' use of social media tools and their view on using it. The research questions are the following:

* What social media are used by academics as a lecturing tool?

* What type of social media is used by academics to enhance student learning?

* Are there differences between academics in a developing country and developed countries regarding the use of social media tools?

The next section provides an overview of what social media is and the awareness thereof. The empirical findings and the discussion of the findings of the developing country and developed countries surveys are presented after the literature review has been executed.

\section{Literature review}

It is acknowledged that electronic communication has become very popular and is a highly preferred means of communication in organisations for a variety of purposes (Ruck \& Welch 2012; White Vanc \& Stafford 2010; Welch 2012). Even though e-mail is a highly preferred method of internal communication the Society for Human Resource Management (SHRM 2012) and Deloitte (2011) stated that there is an increasing trend toward using social media for communication purposes in the workplace. The use thereof in the education environment is therefore a logical progression in the educational process as well.

Social media is defined by SHRM (2011, Para. 1) as "... web-based tools and technologies used to share information and turn communication into interactive dialogue with internal and external audiences through Facebook, Linkedln and Twitter". Mangold and Faulds (2009: 357) define social media somewhat differently as, "... a variety of new sources of online information that are created, initiated, circulated and used by consumers intent on educating each other about products, brands, services, personalities and issues." As a further refinement to describe 
more fully what SM entails the Education Council NZ (2015a) outlines the characteristics of social media as follows:

* Internet based platforms that enable all the users to: create, adapt, share and sustainably reuse the information and content. It enables the users to engage in digital collaboration and dialogue. It provides linkages to create groups, networks and communities.

* Users are able to have, initiate and continue social interactions with peers and other users. Create and maintain their online profiles and IDs.

*. Social media applications are largely public online platforms that are accessible 24/7 through different locations and all the major computer and mobile devices.

* Content and information on social media is largely created by the users, is persistent and can be subject to conditions of use.

Social networking creates a virtual culture based on diversified media systems that uses computer/mobile mediated communication. The best part of a Social Media culture is that the content is created by the audiences and it is based on the principal of sharing and participation. When using social media people not only create content but go on to make conversations and communities using openness and connectedness (Huang, 2014).

Figure 1, presented below, which was compiled by the Education Council NZ (2015a) presents a very good visual outline of what social media components entail and is used for the purpose of contextualising the components of social media.

Let's now focus on what social media is as well as the usage in various developed countries as well as a developing country. The educational publishing company Pearson in the USA regularly executes surveys using representative samples of American academics. It is reported by Seaman and Tinti-Kane (2013: 7-14) saying that more than half (55 per cent) use social media for professional purposes other than teaching at least monthly, but only 41 per cent did so for teaching purposes. Linkedln was the most used site for professional purposes other than teaching. For teaching purposes, blogs and wikis are most used, followed by podcasts, Linkedln, Facebook and Twitter. 
Figure 1. What is Social Media?

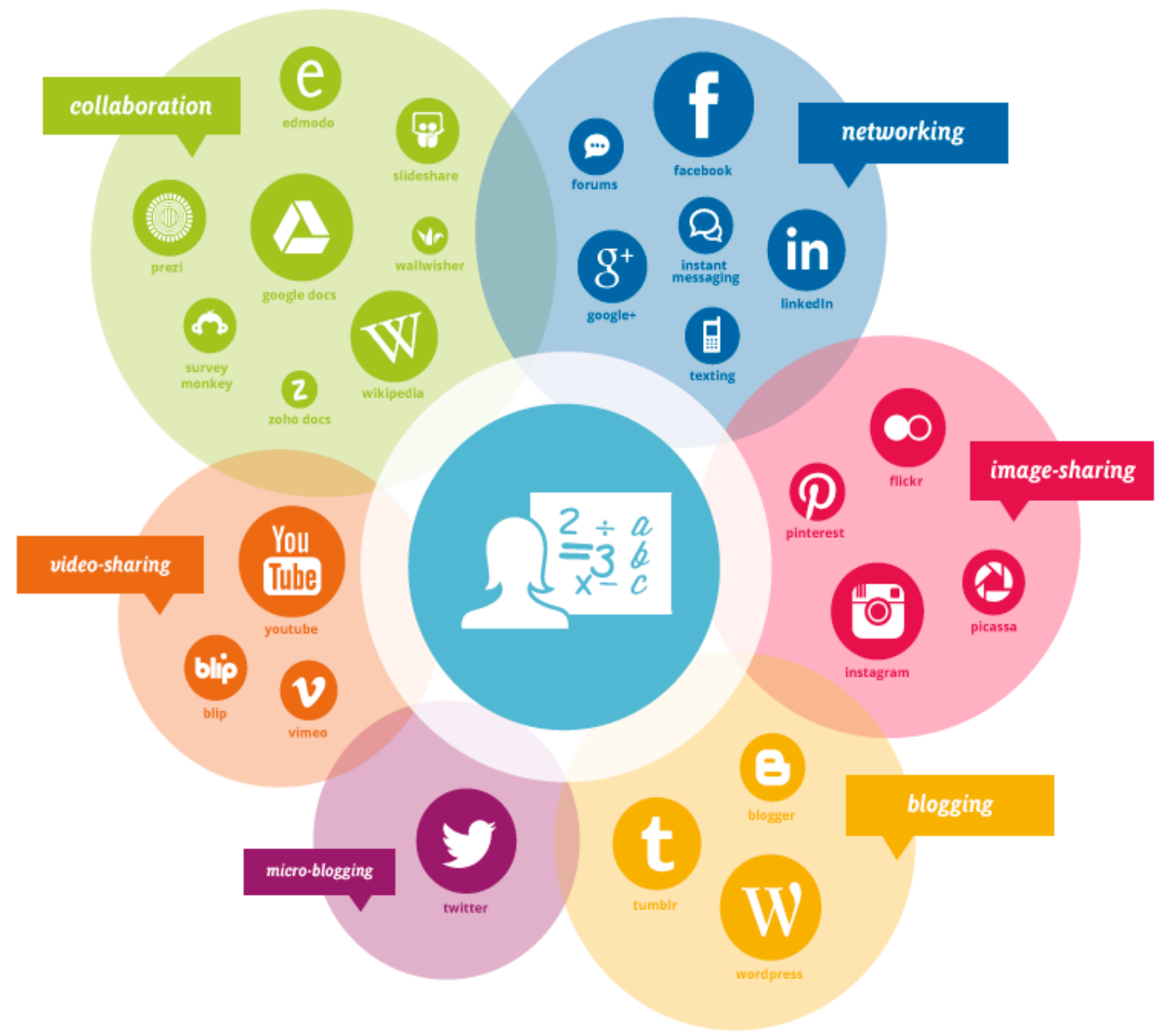

Source: Education Council NZ (2015a)

Social media has the potential of transforming the fundamental nature of education and academic writing as well. Scholarship and knowledge creation is enhanced by using social media due to the sharing and participation culture of social media platforms. Nel (2013) also points out that users of social media should encourage and promote two-way communication so that the information relay is fair and effective for all concerned. Users should also be in a position to utilise innovative ideas from all participants to gain excellence in desired educational outcomes.

Lupton (2014), in her multi country study, states that there have been various published reports and surveys outlining the usefulness, benefits and drawbacks of social media usage by academics and students in recent years. The results and recommendations of research reports 
offer insight into how academics are strategically using social media in order to reap many benefits in their academic endeavours. The benefits of social media include connecting and creating networks, not only with students and other lecturers but also with people outside universities which promotes openness, giving and receiving support and social sharing. The reports and research on social media have largely been positive, however, certain people have also raised concerns in regard to issues related to privacy, professionalism, injudicious use, ethical usage, time pressures and lack of credibility and problems of possible plagiarism. Lupton (2014) highlights the benefits of social media use in academic practices as follows:

* It creates a culture of sharing and building new connections

* It provides real time rapid access to vast professional networks.

* It enables the users to make more direct conversations and influences.

* It helps students to keep in contact with their teachers.

* Provides the ability to chat and start conversations at any point in time.

* Easy to disseminate information to a large audience.

* Strong networking is possible through social media which is otherwise a difficult task.

* Access to unlimited up to date information and support that can be utilized for various purposes.

* Interactions and connections between diversified people which is otherwise not possible.

* It increases the ability to read information greatly as it can be accessed through mobile devices.

* Keep a track of information/opportunities internationally by following key players, leaders and authors.

* Fast and very effective way of communicating with students.

* Great tool to increase student engagement and interaction in class.

Nel et al. (2014:65) outline that in South Africa Facebook and Twitter appear to be the most popular social media tools used across the country and that the trend seems to be to use it more and more in business activities as well. Erasmus et al. (2016) also emphasise in their overview of e-learning that this trend is becoming more prominent in South Africa and that the environment created by it for use by academics is far- reaching and has accelerated so much over the last past 10 years that perhaps $25 \%$ of all learning will take place via electronic means in the next 5 years.

Parker (2015) made a comment regarding developed countries that $84 \%$ of New Zealand students under 25 use Facebook every day. These results clearly indicate that there is a greater awareness and use of social media amongst the younger generation, which would probably include the primary group participating in educational activities to prepare them for their careers. The follow-on would be that the use of social media by academics to communicate and use it as part of their educational tool kit for student education is appropriate, as the majority of younger people own electronic communication devices (Neal 2012). Dixon (2015:9-10) outlines a number of important elements in terms of the awareness and use of social media in New Zealand and claims that four out of five New Zealanders with an internet connection have a social media account, with $87 \%$ using Facebook. It has also become the norm in New Zealand that businesses interact with their clients via social media when dealing with complaints or announcing offers or good deals. There is also an awareness that different 
social media options exist and that communities should use a social platform that suits them personally. Apart from Facebook or Twitter there are also other platforms such as the friendlier picture driven Instagram and on the other hand the more touchy-feely approach of Vine which could also be used. Alternatively, users could use Pinterest. Anecdotally professional users appear to make more use of Linkedln. NZ academics are also encouraged to use social media to help students to grow positive behaviour, and enable them to apply respectful values in all interactions on social media platforms. For educational institutions and academics the use of social media as a tool kit for educational purposes has therefore become imperative to improve educational delivery and learning of students, in developed countries in particular (Retta, 2012).

\section{Methodology}

The research studies discussed in this paper were respectively executed by Lupton (2014) being the developed countries study and Wiid, Nell and Cant (2015) being the developing country study, both using SurveyMonkey to gather data The questionnaires for both studies used similar social media tools to identify its usage frequency. The SurveyMonkey surveys for both studies were closed after being open for two months. Useable responses respectively totalled 204 in SA and in the developed countries 711 . The results of both studies were subject to SPSS analysis.

The results of two of the research studies are compared in this paper to identify similarities and differences between the said countries' academics' use of social media tools.

\section{Comparison of the two surveys' results}

The results for the type of social media used are discussed first, followed by the frequency of use.

TABLE 1: Type of social media tools used

\begin{tabular}{|l|l|l|}
\hline \multicolumn{1}{|c|}{ Social media tool } & \multicolumn{1}{|c|}{ Developed countries\% } & \multicolumn{1}{c|}{ Developing country\% } \\
\hline Facebook & 42 & 84.13 \\
\hline Twitter & 90 & 61.76 \\
\hline Linkedln & 60 & 61.27 \\
\hline Pinterest & 9 & 53.43 \\
\hline Academia & 49 & - \\
\hline MySpace & - & 50
\end{tabular}

Source: Lupton (2014: 14) Wiid, Nel, and Cant (2015:401)

It should be noted that other tools used in the separate surveys, which do not overlap and thus prohibit comparative analysis, are as follows: In the developed countries response are Academica.edu 49\%, ResearchGate 33\%, Personal blog 32\%, You Tube 25\%, Google 21\%. In the developing country results the only other social media tool that was listed was MySpace and scored $50 \%$. 
From the results presented in Table 1 it is clear that Facebook is far more prominent in the developing country than in the developed countries, whereas Twitter on the other hand, is the most prominent for developed countries and much less so in the developing country survey. Surprisingly Linkedln recorded virtually the same score for both surveys. It is surprising that there is a huge difference between Pinterest usage in developed and developing countries.

It can be deduced that developed countries are more sophisticated in their use of social media for academic work by academics in that Twitter features very prominently. Conversely, the use of Facebook does not seem to be as popular in developed countries perhaps because the novelty is still high in the developing country context for academics. It is also surprising that MySpace does not feature in the developed country context at all and this could perhaps be ascribed to the profile of the academic institution which participated in the survey, being primarily an open distance learning institution. This could perhaps be countered by the high use of Academia.edu which is very high in the developed country context.

Let's now analyse the frequency of the use of social media presented in Table 2.

It should be noted that the scales referring to frequency of use for the two surveys are not identical. It is skewed by the fact that for the developing country response, the number of hours per week was used as the scale, whereas for the developed countries it was merely listed which social media was used for academic work and regarded as useful.

TABLE 2: Frequency of the use of social media tools

\begin{tabular}{|l|l|l|}
\hline Social media tool & Developed countries \% & Developing country \% \\
\hline Facebook & 14 & 12.79 \\
\hline Twitter & 83 & 8.73 \\
\hline Linkedln & 14 & 11.2 \\
\hline Pinterest & 2 & 1.83 \\
\hline Academia.edu & 22 & - \\
\hline MySpace & & 1.96 \\
\hline
\end{tabular}

* Exceeding 6 hours per week

Source: Lupton (2014:15) Wiid, Nel, and Cant (2015:401)

Drilling down, regarding the results presented in Table 2, in the developing country the response for the frequency of the use of social media there are noticeable differences between the two surveys. The results are perpetuated from Table 1 namely that Facebook remains the most popular in developing countries, whereas in developed countries, Twitter is head and shoulders above all other social media tools being used. Surprisingly, Linkedln drops 
significantly, but is still in far greater use than Twitter in the developing country survey. Yet, in the developed country survey it has dropped significantly. It is also interesting to note that Pinterest has about equal usage in terms of the context of frequency for both surveys.

In terms of the overall findings, it is clear that there are noticeable differences in the use of social media between the developed countries and developing country survey results. It can be deduced that there is perhaps a difference in sophistication and preference by academics in the context within which they do teaching. It could also be due to the ease of or availability of social media devices by students to benefit from these electronic means of education in the academic environment. There is perhaps also a greater maturity amongst educational institutions and their students in the developed countries than in the developing country survey. This reflects the choice of and preference for the use of particular social media for academic work and the use thereof by academics in the learning environment to enhance learning.

\section{Limitations of the study}

The South African survey, as a developing country study, was undertaken at a single educational institution only, whereas the developed countries survey was open to volunteers from any academic institution. Caution should therefore be exercised in relation to the developed countries study, as it could be suspected that the volunteers were probably prosocial media users already. The results should thus not be taken as absolutely generalizable to the population of academics in the developed countries study. A further note of caution is that the developed countries study included $2 \%$ responses which could be classified as developed countries, but which was included in the overall results for developed countries. Furthermore, the developing country study only focussed on one academic institution which should also be a cause for the results to be viewed with caution. It reflects a very limited snapshot of the need for and use of social media in a developing country.

A comparison of the need for and use of social media from learners' point of view was not addressed in this research reported upon and should be undertaken as a separate future research project. Comparisons with other countries' state of the use of social media is not included in this study and could shed light on the global state of affairs. No attempt was made to investigate the use of social media at secondary school level either, as it was beyond the scope of this research. It could certainly be considered in future research for comparative purposes and could shed light on the readiness of pupils to embrace social media at tertiary level should they continue their studies.

It is suggested that a study be executed to cover various tertiary educational institutions throughout South Africa to gain a more representative view of what the actual use and need for social media is in a developing country's academic environment. Furthermore, a more comprehensive and in depth comparison of a number of developing countries compared to developed countries could perhaps shed more light on the state of the use of social media 
tools in academic teaching. It could also highlight the frequency of the use of social media by academics to identify more robust trends in the exciting new electronic age. However, due to the dearth of data available on comparisons of this nature the limitations are acceptable to identify a profile of this nature, no matter how big the limitations are. Some research based results is better than no profile in the spirit of research instead of mere guesswork.

\section{Conclusions}

It is clear that the use of SM has become an essential aspect of the toolkit of academics to enhance their teaching and to improve the learning environment for students. It is accompanied by the fact that the learning environment can become more interactive and exiting for the learners and also infuse enthusiasm for both academics and learners by employing the tools that are available. The positive outcome is that social media broadens peoples' minds and their perception of things they can do or help them to do.

Although the results presented in this paper should be viewed with scholarly caution, it could provide some interesting insights about the use of social media tools by academics in developed and developing countries. The results, however, become broadly indicative of the types of social media tools which are being used in higher education across various mostly developed countries, as opposed to developing countries.

The results and implications could perhaps be applied to the tertiary educational systems in other countries as well, in spite of the daunting limitations which have been outlined in this paper.

\section{References}

Dixon, G. 2015 Social Media 101. Canvas Magazine. Supplement to the NZ Weekend Herald. 17 January 2015, pp.9-12.

Education Council NZ, 2015a. What is Social Media? Retrieved from: http://academicsandsocialmedia.co.nz/what-social-media.

Education Council NZ, 2015b. Communication and collaboration in learning. Retrieved from: http://teachersacademicsandsocialmedia.co.nz/your-stories/positive-casestudies/communication-and-collaboration-learning

Erasmus, B.J., Loedolff, P. van Z, Mda, M. \& Nel, P.S. 2016. Managing Training and Development. (7th edn.) Oxford University Press: Cape Town

Fuatai, T. 2012. One in five kiwis 'like' Facebook use at work. Retrieved from http://www.nzherald.co.nz/news/print.cfm?objectid=10813136. . 
Huang, H. 2014. Social Media Generation in Urban China: A Study of Social Media Use and Addiction among Adolescents. Heidelberg, Germany: Springer.

Lupton, D. 2014. 'Feeling Better Connected': Academics' Use of Social Media. Retrieved from (Online report) http://www.canberra.edu.au/research/faculty-researchcentres/nmrc/publications/documents/Feeling-Better-Connected-report-final.pdf

Mangold, W. G., \& Faulds, D. J. 2009. Social media; The new hybrid element of the promotion mix. Business Horizons, 52, 357-365.

Neal, D.R., ed. 2012. Social Media for Academics: A Practical Guide. Oxford: Chandos Publishing

Nel, P.S., Werner, A., Botha C., Du Plessis, A.J. Mey, M, Ngalo, O, Poisat, P, \& Van Hoek L. 2014. Human Resources Management. (9 ${ }^{\text {th }}$ ed). Oxford University Press: Cape Town.

Nel, P.S. 2013. New Zealand HR employee communication: Comparing 2000 and 2010 empirical results with forecasts for 2020. Journal of Business and Policy Research. 8(1), 132146. March

Nash, R. 2015. Top five social media tips for 2015. Retrieved from:

https://www.nzte.govt.nz/en/news-and-media/blogs-and-commentary/2015/1/28/top-fivesocial-media-tips-for-2015/ January

Parker, R. 2015. World-first release of Facebook usage in New Zealand [Web log post]. Retrieved from http://blog.marketing.org.nz/2015/05/05/world-first-release-of-facebookusage-in-new-zealand/. May

Rahman, N., Arora, J, \& Kularatne, I. 2014 Employers' perceptions of using social media for recruitment. Asia Pacific Journal of Business and Management, 2014, 5(1), 1-12

Research New Zealand. 2015. A Report on a Survey of New Zealanders' Use of Smartphones and other Mobile Communication Devices 2015. Retrieved from: http://www.researchnz.com/pdf/Special\%20Reports/Research\%20New\%20Zealand\%20Spec ial\%20Report\%20-\%20Use\%20of\%20Smartphones.pdf

Retta, G. 2012. The use of social media for academic practice: a review of literature. Kentucky Journal of Higher Education Policy and Practice: 1(I). 2, Article 7

Seaman, J. \& Tinti-Kane, H. 2013 Social Media for Teaching and Learning. Retrieved from: http://www.pearsonlearningsolutions.com/assets/downloads/reports/social-media-forteaching-and-learning-2013-report.pdf

SHRM 2012. January. SHRM research spotlight: Social media in business strategy and operations. Retrieved from

http://www.shrm.org/Research/SurveyFindings/Documents/Part 4 Social Media Flier.pdf

Taylor, C. 2015. Does Facebook 'unfriending' constitute bullying? Retrieved from http://www.hrmonline.co.nz/news/does-facebook-unfriending-constitute-bullying-206104.aspx

Veletsianos, G. and Kimmons, R. 2013. Scholars and faculty members' lived experiences in online social networks. The Internet and Higher Education, 16. 43-50. 

11 - 12 January 2016, Taj Hotel, Cape Town, South Africa, ISBN: 978-1-922069-95-5

Welch, M. 2012. Appropriateness and acceptability: Employee perspectives of internal communication, Public Relations Review 38(2): 246-254. doi:10.1016/j.pubrev.2011.12.017 Wiid, J.A., Nell, E.C., \& Cant, M.C. 2015. Perceptions of lecturing staff on social media networking systems and their use of it. International Business \& Economics Research Journal, 14(3), 395-406.

White, C., Vanc, A. \& Stafford G 2010. Internal communication, information satisfaction, and sense of community: The effect of personal influence, Journal of Public Relations Research 22(1): 65-84. Doi:10.1080/10627260903170985.

Young, C. 2014. Could the use of eLearning and digital literacy tools improve CAA's business goals of increased student retention and student success? Unpublished MBus thesis. Unitec, New Zealand. 